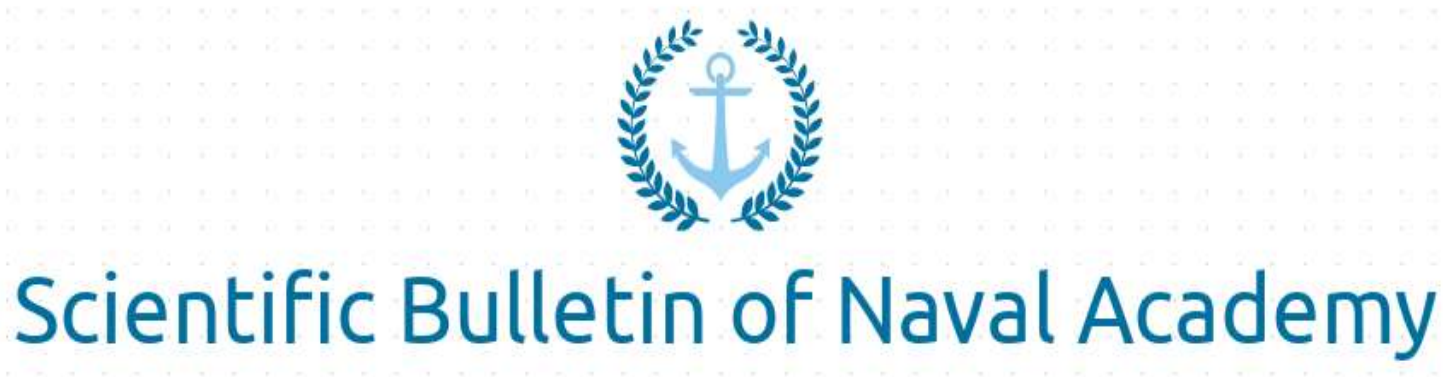

SBNA PAPER • OPEN ACCESS

Digital Flashcards in the EFL Classroom

To cite this article: Apostol-Mates Raluca, Scientific Bulletin of Naval Academy, Vol. XXIII 2020, pg.266-269.

Available online at www.anmb.ro

ISSN: 2392-8956; ISSN-L: 1454-864X 


\title{
Digital Flashcards in the EFL Classroom
}

\author{
Senior Lecturer Raluca Apostol-Mates, Ph.D. Mircea cel Batran Naval Academy \\ Senior Lecturer Alina Barbu, Constanta Maritime University \\ ucamates@yahoo.com \\ alucu013@yahoo.com
}

\begin{abstract}
The starting point of our research has been the assumption that conversation at sea is vital. Broadly speaking, communication arises when there is a lack of information which needs to be filled between the speaker and the listener. The problem with using specialized language in order to achieve this goal has led to a need for alternative teaching approaches meant to facilitate the acquirement and usage of such an intricate lexical domain such as Maritime terminology. Mnemonic educational strategies have proved themselves as useful, beneficial tools for learners of technical English in general and maritime English in particular. Our study aims at highlighting a few aspects pertaining to this topic as well as providing a more practical approach for the ESP classroom.
\end{abstract}

\section{Gamification of EFL classroom}

Both a learning and a teaching technique, deemed as highly useful as a content-conveying tool, gamification is the key for nowadays' classroom of English as a Foreign language.

Gamification is definitely an effective approach to the educational system for two main reasons. On the one hand, it gives a boost of interest on the part of the students motivation them and inspiring them to keep on learning; and, on the other hand, it gives a sense of reward, due to the obvious students' familiarity with games (especially computer games)

A gamification approach is highly relatable to them and makes them feel at ease with this learning tool.

Upon the whole, we speak of gamification as a useful teaching strategy which makes use of gaming instructions and principles by incorporating them into the educational process.

Students of Maritime English are faced with an even bigger challenge than the other students of EFL. Maritime terminology is known to be hard to acquire and hard to teach. And a teacher of Maritime English cannot simply teach lists of words. Therefore, internet-based apps or games are more than welcome in the teaching process. In what follows, we have tried t highlight a few online resources available free-of-charge and that can be successfully used in the Maritime English classroom.

Gamification leads to a better student engagement. Online technology can be exploited for the service of learners and teachers alike. These resources are available without interruption which means that students can use them at their convenient time.

The site www.elearningindustry.com provides its readers with tons of insightful articles related to the intricate domain of e-learning. It is also the best place to download free teaching tools for teachers. Throughout the diverse realm of e-learning flashcards are one of the best option. They are very much alike with card games with the only difference that one has to flip the card by clicking on it and the answer to the respective definition comes up instantly.

There are various apps which are available online free of charge: 
- Quizlet contains two sections. One dedicated to learners and the other dedicated to teachers. In the teacher section those are urged to engage their students in the process of learning by means of interactive material, learning activities and games. According to Ashcroft and Imrie (2014) "Quizlet provides access to millions of sets of flashcards created by users. Cards can be made from scratch or copied and modified from existing sets. Quizlet, like many of the alternative flashcard sites available, allows users to customize their flashcards and several arrangements are possible, including the use of multiple languages and images. The Quizlet site also includes a text-to speech audio function, giving users the option of hearing as well as reading card content. In a recent stud, Quizlet was found to be more effective than using paper flashcards at improving vocabulary test scores" (Imrie, 2014)

- Flashcard Machine is a similar app which also allows the user to create flashcards with the android device and then sync the created set with the app.

- Cram (https://www.cram.com/flashcards/ship-parts-11382870 - link to the flashcard set on Ship Parts created by Alina Barbu)

All of the above mentioned are applications meant to facilitate the incorporation of technology into the classroom. Teaching Maritime English can be really challenging are more too often teachers get the feeling of not knowing where to start. By integrating games into the class one can really give a boost of creativity, improve learners' vocabulary skills and make word acquisition fun and accessible.

\section{Mnemonic Strategies; Flashcards}

Flashcards are easy-to-use and easy to create. One does not need to be a computer genius in order to get by a flashcard generator application or an online tool for that matter.

In his book of 1991 "A Practical Handbook of Language Teaching" David Cross presents the alternative digital teaching solution in general and that of flashcards in particular as a collateral output of a social learning experience. He highlights the importance of cooperative learning which is to imprint The EFL classroom with a sense of fulfillment and self-contentment. The definition of flashcards according to Cross is that flashcards are a vocabulary-building strategy. The ultimate goal of teaching is to make students remember words and grammar structures and from this perspective mnemonic education is a set of strategies designed to help students better memorize new information. It links this new information to knowledge previously acquired through the use of visual or audio cues.

Flashcards represent an educational strategy which combines cues (often visual) based on the student's current knowledge applied to the new information that he or she must learn. They really help the process of remembering key information, as well as facilitating the process of retrieving it for later usage in conversation.

"Flashcards are thought to be a particularly effective deliberate learning tool for studying vocabulary. Indeed, flashcards have been shown to be a more efficient means of learning vocabulary than other de-contextualized deliberate learning strategies such as word lists or dictionary use" (Schmitt and Schmitt, 1995 in Ashcroft \& Imrie Learning Vocabulary With Digital Flashcards).

Researchers like Mastropieri and Scruggs (1990) have argued that mnemonic education has proved its effectiveness as a pedagogical tool as it focuses on the improvement of two major aspects: learning and memorization (Scruggs and Mastropieri, 2000). Mnemonic teaching has proven to be an effective evidence-based practice for improving these two essential aspects (Mastropieri and Scruggs, 1990a; Scruggs and Mastropieri, 2000). Flashcards in particular have shown their effectiveness in improving the ability to remember and understand information.

The mnemonic teaching strategies are classified into several main types which are briefly analyzed below. We have also attempted to examine the implications of using these techniques in the classroom for students of Maritime English, as well as some of the challenges and considerations associated with 
research into mnemonics and its use by teachers. Finally, we present a list of recommended books and online tools to learn more about mnemonic teaching.

There are three forms of mnemonic strategies used primarily to improve retention and understanding of new material in students of Maritime English:

- the visual method,

- the picket method, and

- the strategies using letters (acronyms).

Going back to the particular case of flash cards, we should pinpoint some crucial aspects, as follows:

1. First, flashcards (be them paper-based or digital) endow students of EFL with a sense of control over the whole process of learning and vocabulary acquisition.

2. Second, the possibility to access the set of flashcards containing new vocabulary at students' own pace and convenience creates a sense of space and autonomy which enhances the learning process

3. Third, the fact that flashcards are portable they represent a data base which can be accessed at any time, and the students may intervene and create new grouping criteria of lexical themes to be studied. Similarly, the fact that flashcards stimulate the visual sense creates a highly motivation on the part of the student.

In the particular case of maritime English, only the first method is applicable.

The visual method consists of teaching new words using images.

To teach a new word, the teacher first identifies a word that can be easily represented by an image or a drawing. For example, if the word to be taught is wildcat, which has nothing to do with the most common meaning of the word according to the general public perception; the teacher is going to show the students an image of the onboard installation in question first.

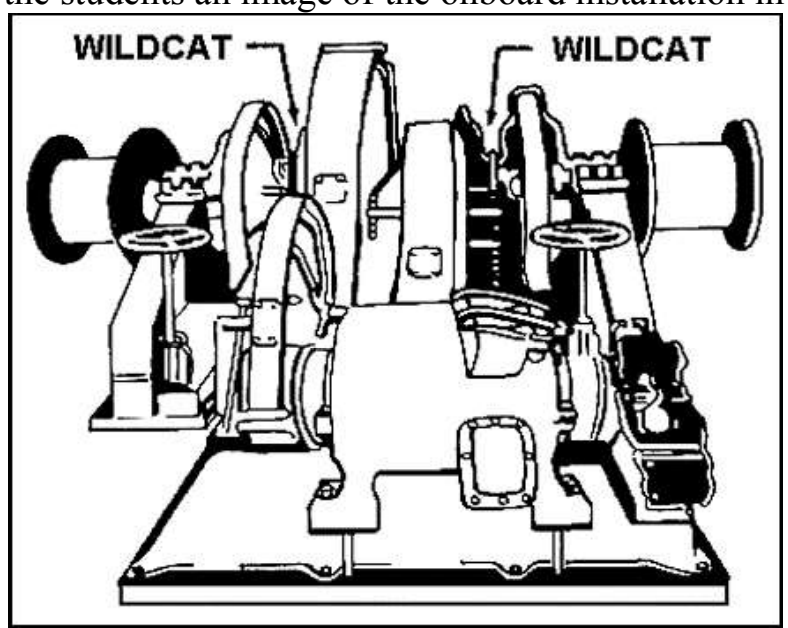

Source: https://fas.org/man/dod-101/sys/ship/beginner.htm

Then, students are to read the definition to be found on the back side of the flashcard.

Similarly, when teaching the international alphabet, students greatly enjoy being provided with flashcards containing a visual prompt, such as two Argentinean dancers and they have to come up with the letter in the international alphabet corresponding to this concept ( $\mathrm{T}$ for Tango)

As mentioned before, learning English as a foreign language is already difficult as it is, since English as a target language is very much different from the source language, in our case Romanian. Learning specialized terminology represents yet another challenge and therefore students need to be provided with a sense of ability to acquire new vocabulary on the basis of prior skills and knowledge. From this point of view, the implementation of flashcards has turned out to be a successful tool in 
improving students' lexis. For instance, when given the word spring without a visual representation of the concept, students fail to infer the maritime-related meaning of the word and invariably come up with the most familiar meaning of the word as one of the four seasons of the year. Consequently, a flashcard containing an image of this type of mooring rope on a flashcard shall definitely provide some useful insight for proper inference and word acquisition.

Vocabulary is beyond any doubt an element of utmost importance. In the maritime environment, learning lexis and how words function in a given context needs to be taken heed of at face value. Using flashcards may significantly help students understand and remember the meaning of new words.

\section{Conclusions}

The ultimate quest of nowadays' teaching approach is how to make memorization easier to students of EFL especially student like maritime school cadets who are faced with the challenge of acquiring technical vocabulary. In order to achieve this goal, teachers have created and used all sorts of methods and teaching techniques. At the end of the day, the most useful and popular method seems to be represented by flashcards. Digital flashcards are obviously more student-friendly, easily accessible and manageable and the that app stores and the internet itself provides users with resources galore, most of them free of charge, is definitely a big plus.

\section{References}

[1] Ashcroft, R. J., Imrie, A. C. Learning vocabulary with digital flashcards. In JALT2013 Conference Proceedings. N. Sonda and A. Krause Editors, Tokyo, 2014 retrived at https://jaltpublications.org/files/pdf-article/jalt2013 064.pdf

[2] Beglar, D., Hunt, A. Six principles for teaching foreign language vocabulary: A commentary on Laufer, Meara, and Nation's "Ten best ideas." The Language Teacher, 2005, 29(7), 7-10. retrieved at https://www.researchgate.net/profile/Batia_Laufer/publication/256479467 Ten best ideas for teachi ng vocabulary/links/54824b360cf25dbd59ea9564/Ten-best-ideas-for-teaching-vocabulary.pdf

[3] Cross, D. A practical handbook of language teaching. London Longman, 1991 at https://www.researchgate.net/publication/228046175 The Handbook of Language Teaching

[4] Foster, H. Building learner-generated vocabulary logs with Quizlet.The Language Teacher, 2009, pp. 33(12), 23-25. at https://jalt-publications.org/tlt/departments/tlt-wired/articles/457-buildinglearner-generated-vocabulary-logs-quizlet

[5] Levin, J.R. Mnemonic strategies and classroom learning : A twenty-one year report card. The Elementary Journal, 1993, 94(2), 235-244. retrived at https://www.jstor.org/stable/1001972?readnow $=1 \&$ seq $=1 \#$ page scan tab contents

[6] Mastropieri, M., Sweeda, J. et Scruggs, T. Putting mnemonic strategies to work in an inclusive classroom in Learning Disabilities Research and Practice, 2000, 15(2), 69-74. retrieved at https://www.researchgate.net/publication/247641750 Putting Mnemonic Strategies to Work in an Inclusive Classroom 